\section{"A pesar de todo, dicho en el vacío es más..."}

Alberto T. Estévez ${ }^{(1)}$

Resumen: Es evidente que una buena intención debería ser pensar y actuar en un escenario del Diseño que pretenda tener la máxima carga de profundidad. Exprimiendo para ello neuronas y tiempo. Es un deber para con el planeta y la sociedad. Y eso se dará mejor si precisamente también el Diseño se abre y se instala entre los campos de las ciencias y de las humanidades.

Por otro lado, podría pensarse que lo factible en Diseño sería sobre todo de lo que ya se tiene experiencia en verlo hecho. Aunque eso sería como el pasado, sería lo conocido, sería historia, desde Adolf Loos a Ludwig Mies van der Rohe. Y si el Diseño se queda cómodamente sólo con lo factible no será agente de cambio social y ecológico. Sin embargo, podría decirse que lo viable sería como el presente, de lo que se empieza a tener primeros ejemplos o prospecciones realistas, lo que se tiene experimentando entre manos que se ve que pronto será factible, y que ya actúa influyendo y orientando los comportamientos sociales. Y por fin, lo deseable sería como el futuro, sería adelantarse, sería proyectar la visión hasta la frontera del conocimiento, metas a las que se quiere llegar. Viendo que sin ni siquiera tocarlo sería un factor de modificación del mundo material.

Así que el deber de investigadores, profesionales y docentes del Diseño (que unificar esas tres facetas da gran ventaja) sería más también abrir e instalar el Diseño en lo deseable. De manera que en cuanto se haga viable sean otros los que se dediquen a lo factible, que por ello no les deja tiempo para hacer prospecciones de viabilidad de lo deseable. Mientras los dedicados a la investigación, profesión y docencia siguen siendo motor que arrastre a algo siempre mejor: hoy, ya en la tercera década del siglo 21, Loos habría superado pensar en "Ornamento y Delito", y Mies actuaría sin mínimos para conseguir lo máximo, pues no trabajaban con lo factible sino con lo deseable, consiguiendo con su vida y obra que fuera viable.

Palabras clave: Diseño - Interdisciplinar - Biológico - Digital - Biodigital - Arquitectura Genética - Ornamento - Naturaleza - Computación.

[Resúmenes en inglés y portugués en las páginas 198-199]

(1) Alberto T. Estévez, Barcelona, 1960. Arquitecto (UPC, 1983: llegó a ser el arquitecto más joven de España cuando aún tenía tan sólo 22 años). Doctor en Ciencias (Arquitectura, UPC, 1990: cum laude). Historiador del Arte (UB, 1994: premio extraordinario final de carrera). Doctor en Humanidades (Historia del Arte, UB, 2008: cum laude). Con ofici- 
na de arquitectura y diseño en Barcelona (1983-hoy), realizando numerosos proyectos y obras. Desde 1983, más de 35 años de docencia e investigación entre las universidades de la UPC, TUWien, UB, Elisava-UPF, HSAK Vienna, UDEM y UIC Barcelona. Fundador (1996) y primer Director de la ESARQ - UIC Barcelona School of Architecture, donde ejerce como Catedrático de Arquitectura. Creador del grupo de investigación, máster y doctorado "Historia, Arquitectura y Diseño" (UIC, 1998-hoy), y del grupo de investigación, máster y doctorado "Arquitecturas Genéticas" (UIC, 2000-hoy), actualmente llamado Máster en Arquitectura Biodigital. Así como fundador-impulsor del Máster de Cooperación Internacional con Alex Levi y Amanda Schachter (UIC, 2004-hoy). Fundó a su vez los doctorados en Arquitectura de la UIC Barcelona, de los que también fue su primer Director. Con más de dos centenares de publicaciones, ha participado en decenas de exposiciones, congresos y comités, y ha sido invitado a impartir más de 100 conferencias por todo el mundo. Acreditado con 6 sexenios de investigación oficialmente reconocidos en el Área de Proyectos Arquitectónicos, es Fundador-Director del iBAG (Institute for Biodigital Architecture \& Genetics). Y últimamente fue Vicerrector-Gerente de la UIC Barcelona (Universitat Internacional de Catalunya).

\section{Sostenibilidad, ciencias y humanidades}

A nadie se le escapa ya cómo está el planeta. Y sin embargo se anda considerando el ir a destrozar alguno que otro más, en vez de pensar en dedicar todos esos millonarios presupuestos a arreglar este. La Luna y Marte por que se tienen más cerca, pero cualquier otro si se pudiera. Además, resulta que irse con todos los gastos pagados a cruzar el espacio interplanetario es mucho más “sofisticado", más cool, que no resolver los problemas urgentes que se tienen a la vuelta de la esquina.

Casi a modo de "manifiesto" sobre este tema es lo que llevó a concebir un proyecto de una casa-prototipo para el desierto, el 3D Printed Sahara House Project, también como ejemplo de "ecología integral" (Estévez, 2020a), diseñado digitalmente y fabricado digitalmente: se construiría imprimiéndolo en 3D, in situ, a escala natural 1:1, con robots, utilizando como parte del material de construcción la misma arena del desierto. Tal cual se hubiera hecho en Marte. Sólo que sin problemas de falta de oxígeno, sin estar a 55 grados Celsius bajo cero como media (con mínimos de hasta $-143^{\circ} \mathrm{C}$ ), sin los vientos extremadamente fuertes y tormentas de polvo que oscurecen el planeta durante semanas e incluso meses. Y todo aquí al lado, sin 3 ó 4 años de viaje espacial. Dando dignidad de vida no a 3 ó 4 "elegidos" sino a miles, por el mismo precio. Efectivamente, lo que en este momento está in crescendo en boca de todos, y que está también en la raíz del cambio de época que se está viviendo, la inteligencia artificial y la robótica, son posibilidades que pueden hacer viable un mundo mejor. Pero sólo si va unido al bien común. Porque si el progreso tecnológico aumenta las desigualdades, no es un progreso real y acabará reventando nuestro mundo. Los avances han de estar siempre orientados al servicio de todos los seres humanos y del planeta que los sustenta. Así además serán avances humanos, por muy tecnológicos que sean, para 
ayudar a fomentar tal dignidad, no para crear mayores divisiones. O se avanza remando juntos en esta barquita de nuestra Tierra, que en sus comienzos no tenía frontera alguna, y que surca el inmenso espacio alrededor del sol, o nos hundimos todos.

Es de la máxima relevancia, crucial, urgente, conseguir la sostenibilidad planetaria, antes de que sea demasiado tarde. (Casi) todos están de acuerdo. Para ello, cada uno, desde su campo de acción y de vida debe empeñarse en lograrlo (Estévez, 2020b). Ningún acto es ya indiferente, para facilitar la sostenibilidad o para dificultarla. Y en este mundo, cada vez más poblado pero con el mismo número de recursos naturales limitados que desde sus orígenes, sólo la suma de todos los miembros de la sociedad puede resolver de alguna manera tal inmenso problema, que ahora se ha levantado como el más alto muro que barra el futuro próximo. Entonces, será de la competencia y responsabilidad de los diseñadores resolver la sostenibilidad de la parcela que tienen encomendada, el Diseño. Ayudando así con ello a todos: es un deber para con el planeta y la sociedad.

¿Y cómo plantear un Diseño sostenible? Hay que mirar alrededor, a la naturaleza (Estévez, 2020a), un pozo sin fondo de lecciones de sostenibilidad y eficacia, espejo eterno de inspiración para el Diseño. Y no sólo de inspiración, sino sobre todo de aprendizaje (bio-learning), que es lo que hace realmente falta. Pero si cada uno no hiciera lo mismo en su área y en su vida, sería del todo inútil plantear un Diseño sostenible. Jamás la humanidad entera ha tenido que afrontar algo de esta magnitud. Con lo cual es como si se le planteara al ser humano una última prueba de inteligencia: ¿eres lo suficientemente inteligente para resolver este problema? Pues sino ya no mereces vivir en esta Tierra, que en realidad es un regalo con el potencial de ser paraíso, a poco que se sepa hacer bien.

Es evidente que la intención debe ser pensar y actuar en un escenario del Diseño que pretenda tener la máxima carga de profundidad. Debe tenderse a la excelencia, ¡claro que sí! Buscar la perfección, aunque se vea cuán difícil es conseguirla. Sin desesperar, por que lo normal será que nunca se llegue a ella. O poca altura tendría si pareciera alcanzarse. Pero en el intento son las neuronas y el tiempo lo que debe exprimirse. Concentrados, buscando estrategias y caminos, para mayor eficiencia. Sabiendo que como factor de eficiencia ya no puede contarse sólo el coste en dinero. Ahora entra la sostenibilidad en juego, en todo y para todo, aunque suponga más gasto económico. Pues hay cosas que ya no tienen precio. Por ejemplo, la extinción de una especie no tiene precio. Perder una sola secuencia de ADN propiciatoria de vida es algo inconmensurable, de un valor inmenso e irrecuperable. De la misma manera que un Diseño realmente instalado y abierto entre los campos de las ciencias y de las humanidades es indudablemente mejor, de más alcance y más profundo, con mejor visión, convirtiéndose por tanto igualmente en un factor de eficiencia. Sólo que es la formación personal lo que incide en esta cuestión. Pues estar entre las ciencias y las humanidades no es no saber ni de ciencias ni de humanidades. Sino aprender ciencias y humanidades. El reto es pues mucho mayor, y la educación dura la vida entera.

(Permitase aquí un pequeño apunte autobiográfico entre paréntesis, pues puede ser útil, especialmente para los jóvenes. Primero recibí mis correspondientes 6 cursos académicos de la carrera de arquitecto, en Barcelona. 12 semestres según lo que duraba antes, eligiendo precisamente como especialidad "Construcción" en los dos últimos años, que era entonces la especialidad más científica y técnica. Y 
luego cursé 6 años de humanidades: dos de filosofía y 4 de historia del arte. Pues, que nadie dude del bagaje que esto da para diseñar, y que se debe recomendar vivamente a todos y todas. Nunca es tarde para ello).

No parece haber controversia en esto. Todos, desde el sentido común, entenderán que hay que dominar las ciencias y la técnica que convenga al caso para diseñar lo que sea, para lograr algo superior. De la misma manera que no habrá duda en reconocer la mayor calidad de lo diseñado si queda imbuido de las humanidades y hecho con arte, como se suele decir. Son dos caras, pero de la misma moneda. Y su valor incluye ambas caras, inseparables, ciencias y humanidades, dando sentido una a la otra. Como lo coloquialmente referido a esa realidad humana de cuerpo y alma, lo material y lo espiritual, una sola entidad, donde el auténtico valor reside en la capacidad de ir ambas a una. Como la inacabable discusión secular sobre la función y la forma: igualmente, las dos caras de la misma moneda. No hay desigualdad, o no debería haberla. Y si una se hace mayor, agranda a la otra. Es el nexo de unión entre ambas lo que las hará ser algo superior: la inteligencia con la que se trata tal nexo, función y forma, como ciencias y humanidades, como cuerpo y alma. Y si tal reto se erige como algo inabarcable, para eso hay algo que se llama trabajo en equipo e interdisciplinar. Si bien tampoco es que sea fácil. Sin embargo, todo ello es deseable, es viable y es factible. Pues, no hay que esperar más para ponerse manos a la obra, cada uno, cada una, sostenibilidad, ciencias y humanidades.

Considérese ahora algo sobre "lo factible, lo viable y lo deseable", especificamente en Diseño...

\section{¿"Lo factible", es el pasado?}

Seguramente pudiera parecer que "lo factible" en Diseño es sobre todo de lo que ya se tiene experiencia en verlo hecho. Pero esto es como si fuera ya el pasado, es lo conocido, es historia, desde Loos a Mies. Y si el Diseño se queda cómodamente sólo con lo factible, no será agente de cambio social y ecológico.

Pues, en esta tercera década del siglo 21, con todos sus argumentos ya obsoletos, Loos habría superado hace tiempo pensar aún en "Ornamento y Delito" (Loos, 1993). "Ornamento y Crimen", como no tan bien traducido ni entendido repiten algunos en español, quizá por haberlo visto también escrito en inglés así: "Ornament and Crime". Entonces, vale la pena traerlo a colación a estas páginas. Para celebrar a su vez algunos redondos aniversarios. Por ejemplo, hace exactamente 90 años, en la Viena de octubre de 1930, él culminaba los dos volúmenes recopilatorios de sus escritos principales, bajo los títulos de Ins leere gesprochen y Trotzdem, traducible respectivamente por Dicho en el vacío, o Dicho al vacio, y A pesar de todo, o Pese a todo. (Una de las cosas más queridas que traje de mis estancias en Viena fue la primera edición original de Trotzdem, publicada en 1931, ilustrada con la Figura 1, sin obviar en ella cierta ironía que Loos incluía siempre en sus escritos. Esta vez cifrando también las coincidencias de fechas personales acabadas en ceros). Ahí puede verse que Loos, en su Prólogo de Trotzdem, decía: 
"De treinta años de lucha yo he salido como vencedor: (...) los dos volúmenes (...) coleccionan los documentos de la lucha”. Y entremedio añadía: “yo he liberado a la humanidad del ornamento superfluo. 'Ornamento' era antes el epíteto de 'bonito'. Hoy es gracias al trabajo de toda mi vida, un epíteto de 'menos valor'. (...) los dos volúmenes 'dicho en el vacío' y 'a pesar de todo' coleccionan los documentos de la lucha y yo sé que la humanidad algún día me lo agradecerá, cuando el tiempo ahorrado beneficie a aquellos que quedaron excluidos de los bienes del mundo".
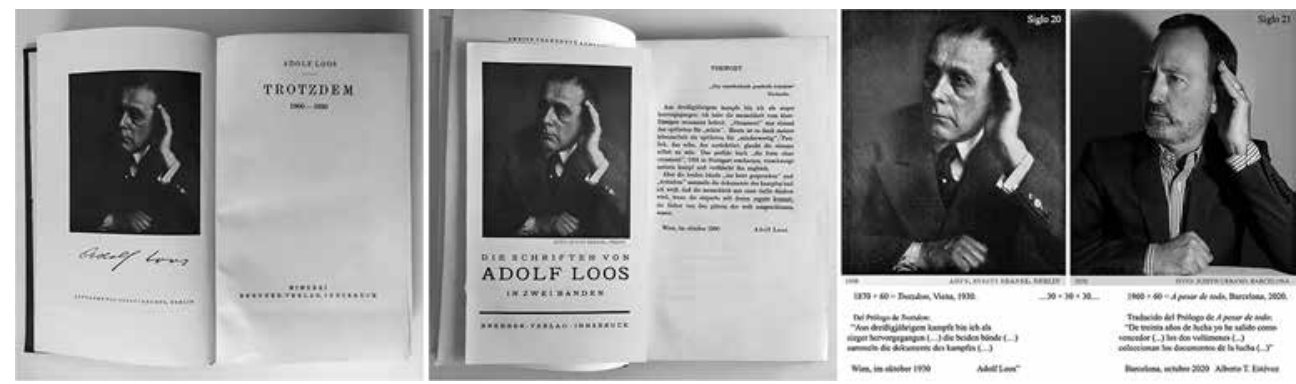

Figura 1. Primera edición original de Trotzdem (A pesar de todo), y fotos comparativas de dos siglos: imagínese en color la de la derecha, como es originalmente, para entender mejor esta comparación, del blanco y negro al color (fotos del autor).

Resulta que leído a fecha de hoy Loos ya no tiene como justificar el haber "liberado a la humanidad del ornamento". Ya que por ejemplo, para darle "mala prensa" al ornamento, lo hacía equivaler a los tatuajes que se infligen los papúas y los delincuentes en su piel, poniéndoles como modelo de poco civilizados. Como igualmente lo serían entonces quienes diseñasen y comprasen piezas ornamentadas. Posiblemente Loos tendría problemas de libertad de expresión si publicara sus textos hoy. Véase sino alguna de las perlas que dejó por escrito: "La persona moderna que se tatúa es un delincuente o un degenerado. (...) Los tatuados que no están en prisión son delincuentes latentes o aristócratas degenerados" (Loos, 1931). Cabe imaginarse ahora a todos los tatuados que leerán estas líneas con una sonrisa, cuando hace años que el tatuaje se ha puesto de moda en el mundo entero y en todas las clases sociales. ¿Por qué? Seguramente ¿por una necesidad humana? Ya que cuesta dinero, algo sí duele, y conlleva cierta irreversibilidad, cierto compromiso de un "para siempre". Una necesidad no físico-fisiológica, por supuesto, no relacionada con hambre, sed, calor, frío, cansancio, comodidad, salud corporal, economía para tener lo mínimo que cubra todo eso. En definitiva, lo que el racional-funcionalismo se volcó en solucionar. Que no 
son más que las mismas necesidades de cualquier ser vivo: los animales ni se ornamentan ni necesitan ornamento alguno. Por tanto el ornamento queda como una necesidad exclusivamente humana. Llámese como se quiera llamar: una necesidad psicológica, anímica, emocional. En cualquier caso es rastro de nuestra dicotomía antropológica, de lo que coloquialmente llamamos cuerpo y alma, o espíritu, o psique, o lo que sea que acordemos en sustantivarlo.

¿Quizá además ha aparecido tan extendida últimamente esta moda del tatuaje por que el Movimiento Moderno negó el ornamento y lo simbólico a la humanidad en sus casas? Y con ellas a sus enseres, muebles y paredes, ¿y también por eso se tatúa uno mismo? A la vista de esto, el Loos de hace 90 años habría muerto ipso facto del susto si de pronto despertara en esta sociedad. Aunque seguro que un Loos que no hubiera muerto hasta hoy habría evolucionado en sus propios argumentos.

Y con Mies pasaría tres cuartos de lo mismo, con su "beinahe nichts" (traducible por "casi nada"), con su famoso "menos es más" (Mies, y Neumeyer, 1995). Cuando su lógica de la reducción extrema, de la neutralidad radical, de la desaparición prácticamente total de lo aparente, ha sido abordada por la tremenda complejidad y dramática contradicción en que ha desembocado nuestro mundo actual. Que sin duda de vivir hasta hoy Mies habría igualmente evolucionado. Para ejemplificarlo se aportan otras comparativas de fotos. Por ejemplo, en la Figura 2 se aprecia un diseño de sillón de especial complejidad. Se trata de una pieza de la serie Hyperboloid Barcelona Furniture, del autor que firma estas líneas, donde el reto era explorar los límites tecnológicos de concepción, diseño y fabricación de hoy día. Siendo absolutamente coherentes con los medios de dibujo y manufactura digital más novedosos. De forma que este diseño sólo pueda concebirse y diseñarse digitalmente, y sólo pueda producirse con impresora 3D robótica, a tamaño natural, y de una única pieza continua. Y con material biodegradable como es el PLA (ácido poliláctico), que se deriva de materias primas naturales y renovables, como el maíz. O sea, estos muebles no podían ser ni concebidos, ni diseñados, ni fabricados antes que el actual presente. Es decir, son hijos de su época. Mientras que los de Mies no podían ser ni concebidos, ni diseñados, ni fabricados antes de su propia época. En cambio ahora ya se cumple casi un siglo que se hicieron viables gracias a él (y a otros de sus contemporáneos), siendo factibles sin problema hasta hoy. Es decir, son hijos de una época pasada. 


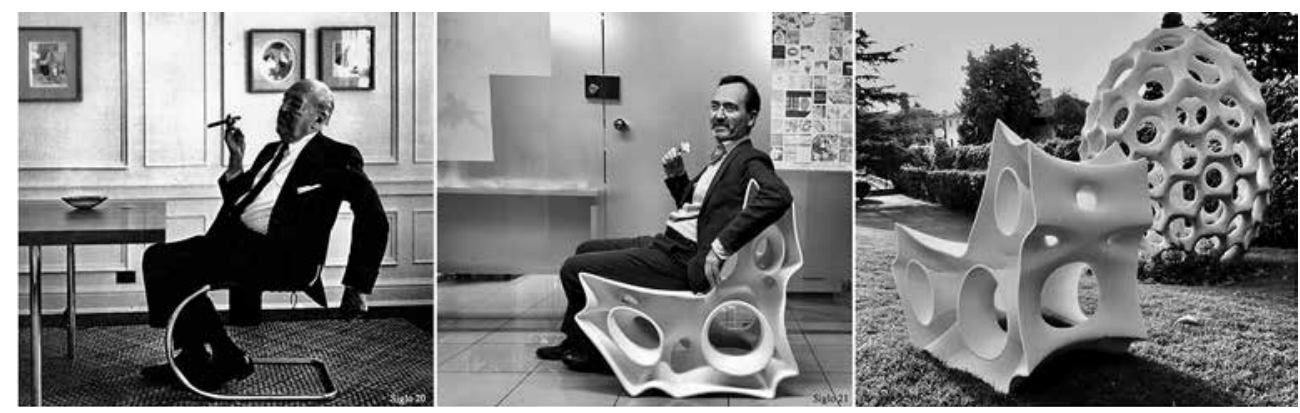

Figura 2. Izquierda y centro, fotos comparativas de dos siglos, el siglo 20 con Mies a la izquierda, y el siglo 21 en el centro (imagínese esta foto en color, como es originalmente, para entender mejor la comparación, del blanco y negro al color) Derecha, Alberto T. Estévez - GenArqOffice, sillón de la serie Hyperboloid Barcelona Furniture (2019), y BioDigital Barcelona Pavilion al fondo (2008-09), diseñados y fabricados digitalmente. (Fotos del autor).

Y ya son tres familias enteras distintas las que desde el año 2010 va diseñando y produciendo este autor bajo el nombre de BioDigital Barcelona Furniture Series. Tres series completas de mobiliario (silla, mesa, taburete, sillón, banco, etc.), de formas complejas, sólo viables y factibles con ordenador y con impresoras 3D de gran tamaño (Figura 3): las series Radiolaria Barcelona Furniture, Hyperboloid Barcelona Furniture y Voronoi Barcelona Furniture. Su armonía, y por tanto su percepción de belleza, queda asegurada por su unidad, coherencia y continuidad computacional (característica del organicismo digital), al quedar regidas cada una de sus partes y su conjunto por las ecuaciones matemáticas propias que ordena el software gráfico usado. Y su complejidad formal asegura también un mayor deleite e interés, al magnetizar más su atractivo a la percepción humana, que tardará más en entender y procesar que una forma simple. Tal como sucede también en el magnético atractivo que el fuego (las hogueras), el agua (las olas), el aire (las nubes), y la tierra (las rocas), ofrece al ser humano. Cuando igualmente se evidencia en todo ello su unidad, coherencia y continuidad física (propia de la naturaleza), regidas cada una de sus partes y su conjunto simultáneamente por una única ley física. Mientras que un ć́rculo, un triángulo y un cuadrado, rápidamente percibidos en su simplicidad, "aburren" enseguida, y dejan por tanto de interactuar, de "acompañar": función también necesaria a cumplir para el ser humano. 

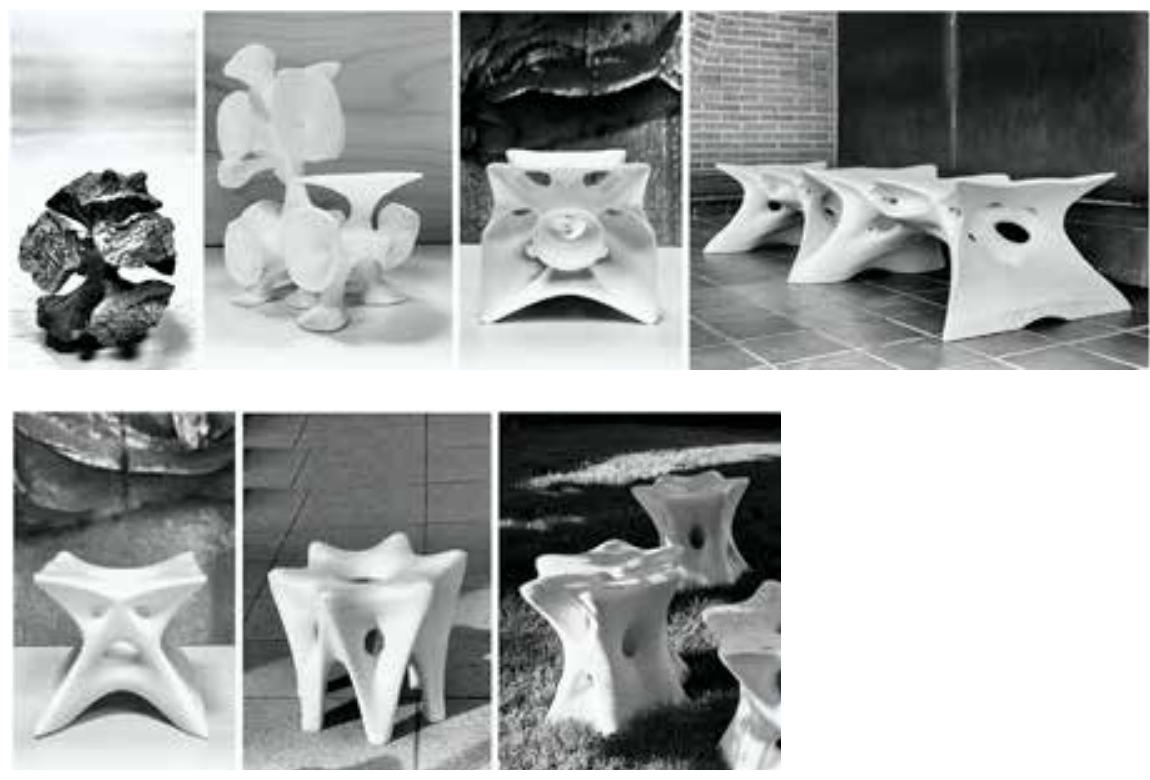

Figura 3. Alberto T. Estévez - GenArqOffice (colaboradores: Pablo Baquero, computational designer, y Noumena), BioDigital Barcelona Furniture Series, 2010-20 (fotos del autor). Izquierda, fruto de ciprés. De izquierda a derecha, silla y banco individual de la serie Hyperboloid Barcelona Furniture (2019-20), y banco doble, individual, taburete de 6 patas y taburete de la serie Radiolaria Barcelona Furniture (2010-20). Digitalmente diseñado, está fabricado en PLA biodegradable, con una impresora 3D robótica de extrusión. Siendo el PLA un polímero biodegradable que puede producirse a partir del ácido láctico, extraíble de cultivos como el maíz. Esto lo hace ideal en posibles áreas pobres económicamente pero con esos recursos agrícolas.

No hay "tatuaje" ni ornamento alguno en esos muebles, pues todo lo que se ve es el ADN de su propia "especie". El “ornamento" (entrecomillado) pasa a ser su complejidad, enmarcada en su unidad, coherencia y continuidad, computacionalmente. Como genéticamente sucede en la naturaleza, sea un tigre, un elefante o una jirafa. Así, esos muebles se configuran como lo haría cualquier ser vivo, y en biodiversidad. Algo que la gente recibe a su vez como admirable en la naturaleza.

Sin embargo Hermann Muthesius fundamentó al racional-funcionalismo más duro del Movimiento Moderno con argumentos tales como este (tomado previamente de Francis Bacon): "Häuser sind zum Wohnen und nicht zum Anschauen". Traducible por "las casas son para vivir y no para ser admiradas" (Estévez, 2009b). Lo cuál choca de nuevo de frente con la realidad secular del ser humano, que necesita profundamente sentirse orgulloso de su casa, o de cualquier otra cosa que tenga o que sepa. Y que necesita justamente ser admirado por tener una casa admirable, unos muebles admirables, unos objetos admirables, o 
unos tatuajes admirables. Es una necesidad real, por tanto una función más a cubrir por parte de los diseñadores: "un regalo de navidad que funciona", que diría acertadamente Philippe Starck para referirse a sus propios diseños. Algo que despierte ilusión, emoción, que por tanto "acompañe", y no sólo que se use de manera indiferente y anónima, por perfecto que sea su funcionamiento.

Entonces, concluyendo, si lo factible, lo más habitual, donde hoy en día nadie "te pone pegas" para su ejecución, es este mundo loosiano y miesino, sin ornamento e inmanente, lo deseable sería un entendimiento contemporáneo del "ornamento" (entrecomillado). Y viable ya lo es...

\section{¿"Lo viable”, es el presente?}

Y siguiendo con lo planteado, quizá entonces "lo viable" sería como el presente, de lo que se empieza a tener primeros ejemplos o prospecciones realistas, lo que se comienza a tener algo experimentando entre manos que se ve que pronto será factible, y que ya actúa influyendo y orientando los comportamientos sociales.

Mientras, los academicistas y comercialistas del establishment que detentan el poder, oficial o no, aposentados en sus efímeras sillas que imaginan estar en la cima, siguen inalterables, miopes y despistados, sólo inmersos en lo factible, en el pasado. Incluso, barrando el futuro y marginando a quién lo anuncia, y por ende a la sociedad entera. Hace poco, uno de estos, que ha llevado siempre como mínimo 15 años de retraso, es decir una generación entera, exclamó con hueca pedantería en foro público: "el estilo internacional está muerto". Y expuso sus dudas delante de todos, sobre no saber lo que tocaría ahora. Aunque su primera ignorancia fue declarar en este siglo 21 tal defunción, como si fuera un gran descubrimiento, de lo que murió hace muchos años. Sólo le contesté, sin aspavientos y "de callada manera", que hacía ya veinte años que llevaba enseñando "lo que tocaría ahora". Por otro lado, es comprensible que quien anda todo el día ocupado gestionando su propio despacho profesional no pueda pensar a fondo, ni investigar en lo que ha de venir. Y no hay falta de honor en ello. Cada uno tiene su justo sitio en este mundo, y de todos hay necesidad. El problema es si no se reconoce cuál es su lugar, y se quiere aparentar estar en más de los que le toca a uno. Así, como no está al día de por donde van los tiros, podría incluso imaginarse que lo que hace es investigación y que imprime progreso. Pero la realidad es que está estancado sólo en lo factible, pues le va el negocio en ello. Y ve como meta aún no factible lo que ya sería viable. Pensando que ese presente viable es sólo un futuro deseable. Futuro que en realidad ni se lo huele, hasta que esté tan presente que en cuanto se ponga a ello será ya pasado. Ante esto la única redención posible es algo de humildad, vivir con honradez, y no zancadillear al que corre delante. Sino más bien al contrario, alentar y ayudar en lo que uno pueda, pues o se va todos a una o se nos hará tarde.

Y es que el tiempo (y la evolución del Diseño) parece que sea como el agua, que corre rápido bajo nuestros pies del presente, sin detenerse, mientras se mira hacia adelante, a la alta e inalcanzable cascada del futuro. Y sólo si se mira hacia atrás se verá el agua estancada del pasado. Mientras que quién duda de su momento es que no está mirando donde toca: 
donde toca mirar en cada momento, y hacia adelante. "No miren lo que yo hago. Miren lo que yo vi", que diría Luis Barragán (2000). Y ahora toca mirar la naturaleza. Que como se decía antes es pozo insondable de bioaprendizaje (bio-learning). De hecho siempre "tocaría" mirar a la naturaleza. Ya que la naturaleza también es como el agua, y la tenemos en el pasado, en el presente y en el futuro. En lo factible, en lo viable y en lo deseable. Y es cierto que últimamente un mayor número de gente está convirtiendo el mirar a la naturaleza (para su quehacer) en una tendencia cada vez más extendida. Términos como biomimética y biofilia se convierten más y más en una moda. Por eso, se entiende bien cuando Loos decía que "De treinta años de lucha yo he salido como vencedor". Pues llevamos veinte desde la fundación del Genetic Architectures Research Group \& Office, y del Máster en Arquitectura BioDigital, y sí que se percibe en los últimos años un significativo crecimiento de tal corriente. Esperando no tener que aguardar otros 10 años para salir vencedores: tal como está el planeta, o vencemos todos o perdemos todos.

Entonces, paradójicamente, aunque la naturaleza ha sido la primera fuente primigenia del ornamento humano - una corona de flores, un collar de conchas, una pluma en el pelo- al mirarla uno se percata de que no hay ornamento alguno en ella: si se tomase el entendimiento de ornamento en el sentido loosiano y miesino de algo superfluo, inútil, innecesario. A los seres vivos no les sobra nada. No se les puede quitar nada de lo que les conforma sin dañarlos de una u otra manera. Todas sus formas, estructuras, coloraciones, están íntimamente ligadas a sus sistemas y procesos, a sus funciones, cuya primera y más básica función es simplemente "vivir". Pero de manera generosa, pues no es sólo vivir egoísta y aisladamente, y morir, sino que es vivir y dar vida, como segunda función enseñada por la naturaleza. Que por cierto, si en los seres vivos todo parece diseñado con altas prestaciones de eficiencia, de mínimo gasto en relación al máximo rendimiento, desde la conformación de los huesos hasta la de una hoja por pequeña que sea, curiosamente, la función de la reproducción es en la que la biología se vuelca de manera magnánima. Sea lo que sea, desde flores a mamíferos, pasando por todo lo demás. Cuando también podía haberse resuelto con mayor precisión. Algo que alienta a ver una metáfora que podría asociarse a esta observación, para aprovechamiento y solaz -diríase- poético. Como metáforas pueden entenderse en todo.

Si bien, en el caso del ser humano, según se ha anotado antes, merced a su realidad antropológica dicotómica, doble, dar vida se puede hacer de dos maneras: dar vida física y dar vida metafísica, o psicológica, o anímica, o, de nuevo, llámesele como se le quiera llamar. Así esa función en el caso de la humanidad es más compleja, pues puede haber gente que dé más vida al resto que no el que tenga una extensa prole, y viceversa. De ahí que la idea sobre escribir un libro, plantar un árbol y tener un hijo se haya hecho tan popular. Pues con estas tres acciones se da vida, física y metafísica. Y tan crucial es una vida como la otra. Cuando se constata que no faltan suicidios entre los que tienen todas sus necesidades físicas resueltas.

Y volviendo a lo tratado en anteriores párrafos, en efecto, el único ser que se ornamenta a si mismo y que ornamenta lo que le rodea, en el sentido que se está comentando aquí, es el ser humano. Que hasta convierte el ornamento en una necesidad. Viendo la naturaleza como admirable para ornamentar y ornamentarse, desde la primera reacción de biofilia que hubo en la historia de la humanidad. Y no hay ornamento "artificial" -apresurada- 
mente definida esta palabra- que supere lo natural tomado como ornamento. Concluyendo que el ornamento para las personas, si es dador de vida emocional nunca es superfluo, sino lo contrario, necesario. Y esto lo sabía bien alguien como Antoni Gaudí, campeón de aprender de la naturaleza desde sus más íntimos secretos y leyes según decía (Estévez, y Urbano, 2020). Entonces, para este presente, para este siglo 21, se erigirían mejor las palabras "Ornamento y Naturaleza" en vez de "Ornamento y Delito", que eran del pasado siglo 20.

Así como que es la biodiversidad de la naturaleza la que alienta el ornamento y la creatividad. Cuando equivocadamente de nuevo se entendió por parte de los racional-funcionalistas otra de esas famosas frases que convirtieron en credo para hacerse fuertes: "form ever follows function" (Sullivan, 1896), "la forma (siempre) sigue a la función”. Y todo el que no se ajusta estrictamente a esto es tachado de formalista, como uno de los peores insultos que pueden lanzarse a un diseñador. Y entonces le siguió el tremendo error del convencimiento de "la buena forma" ("die gute Form"), de que habría una única forma ideal para cada función, y de que por tanto desviarse de tal tipo (a tipificar) o estándar (a estandarizar) sería anatema. Pobre Louis Sullivan, que ornamentaba ricamente sus edificios, ver tan tergiversado su discurso. Nacido de su observación de la naturaleza, pensó en que de ella se aprende la maravillosa adecuación de la forma a la función. Sí, la forma sigue a la función pero ¡de infinitas maneras distintas!, y todas igualmente buenas: es la inmensa biodiversidad la que nos lo demuestra. La función del moverse (nadar, volar, reptar, andar, etc.), la función del agarrar (tentáculo, garra, lengua, mano, etc.), la función de la protección (escamas, plumas, conchas, pelos, etc.). Incluso en apenas unos pocos metros cuadrados del mismo prado, con el mismo clima y la misma tierra, para simplemente la función de la polinización, hay decenas de flores diferentes, grandes y pequeñas, solitarias y arracimadas, con pétalos y acampanadas, de todos los colores.

No obstante, ahora, en el siglo 21, ya incluso con el conocimiento hasta de la genética por medio, resulta que es al revés: la función sigue a la forma. Los anti-racionalistas de los años 60 lo decían simplemente a modo de boutade, pero hoy se sabe que es una razón biológica. Las células crecen sin conocer a qué función servirán, todas iguales desde un mismo y único origen, que se irán diferenciando poco a poco merced a un mismo y único ADN. Y lo primero que va saliendo es la forma que esas células van a ir adquiriendo, sea esta funcional o no. Es sólo después - o casi mientras- que cada función necesaria se irá ajustando a las formas que van resultando. Y está claro que luego cada forma se va seleccionando, perdurando o muriendo en relación a su eficacia funcional, tanto en su parte como en el todo. Demostrando tras millones de años de procesos la espléndida multiplicidad de soluciones viables, la inconmensurable riqueza que se nos ofrece con ello. Es el observar y aprender de la naturaleza más a fondo lo que definitivamente ayudará a entender más y a superar mejor el presente hacia el futuro. 


\section{¿"Lo deseable", es el futuro?}

Y por fin, quizá podría pensarse que "lo deseable" sería como el futuro. Adelantarse, proyectar la visión hasta la frontera del conocimiento, metas a las que se querría llegar. Pues se aprecia que lo deseable es un factor de modificación del mundo material, sin ni siquiera tocarlo. Y ahí es donde las nuevas tecnologías ofrecen una capacidad transformadora que hay que aprovechar. No hay más que echarles mano, a las herramientas biológicas y digitales, ya cada vez más asequibles a todo tipo de público, para ayudar a la concepción del Diseño (Estévez, 2019). Aprendiendo (bio-learning + machine-learning) de la inteligencia natural y de la inteligencia artificial: naturaleza y computación. Creando realidades de arquitectura y diseño de lo que podría llamarse el organicismo digital, mediante la bio-manufacturing y la digital-manufacturing. Nace entonces la fusión del entendimiento de lo biodigital, aplicable al Diseño, donde llevamos los últimos 20 años trabajando desde la investigación, la profesión y la docencia, ahora aunadas esas tres patas en el iBAG, el Instituto de Arquitectura BioDigital y Genética, de la UIC Barcelona (Universitat Internacional de Catalunya), que enmarca tanto el Genetic Architectures Research Group \& Office como el Máster de Arquitectura BioDigital.

Pudiéndose definir de entre esos términos los menos oídos de la siguiente manera:

- Bio-learning, contrapuesto a machine-learning, bio-aprendizaje, lo que podemos aprender de la naturaleza (biológica), de los seres vivos, en todos sus aspectos, formales, estructurales, sistémicos, procesuales, etc., en beneficio del desarrollo de nuestro entorno humano. Que no debe confundirse con biomimética, pues ésta a menudo se entiende como reducida tan sólo a una imitación formal, descerebrada y superficial de la naturaleza.

- Natural intelligence, contrapuesto a artificial intelligence, inteligencia natural, la que puede observarse en la naturaleza (biológica), de los seres vivos, en todos sus aspectos, formales, estructurales, sistémicos, procesuales, etc., de dónde "bio-aprender" su funcionalidad, la manera en que resuelven sus necesidades y posibles problemas que se presenten, sus habilidades, destrezas y experiencias.

- Bio-manufacturing: contrapuesto a digital-manufacturing, bio-manufactura, lo que puede manufacturarse, fabricarse, producirse, con células vivas, sea por procesos genéticos o mediante bio-impresoras 3D de células vivas. Lo que aprovecha el propio potencial del $\mathrm{ADN}$, su capacidad para crecer y desarrollarse de manera autónoma. A la vez que se erige como una vía de perfecta sostenibilidad, al configurarse como cualquier otro ser vivo.

Y en estas estamos, investigando también el bio-manufacturing (Figura 4). Cómo crear estructuras, objetos, espacios, con células vivas, sean estas vegetales, de carne o de huesos, con la adquisición de bioprinters 3D. El problema actual sobre esta tecnología es que replica lo que ya pasó con las impresoras digitales $3 \mathrm{D}$, que al principio estas tenían una gran limitación del tamaño a imprimir, y en cambio ahora ya pueden imprimir por fin casas enteras. Aunque se estén haciendo con formas del pasado, no coherentes, sin aprovechar las potencialidades que tales máquinas permiten. 

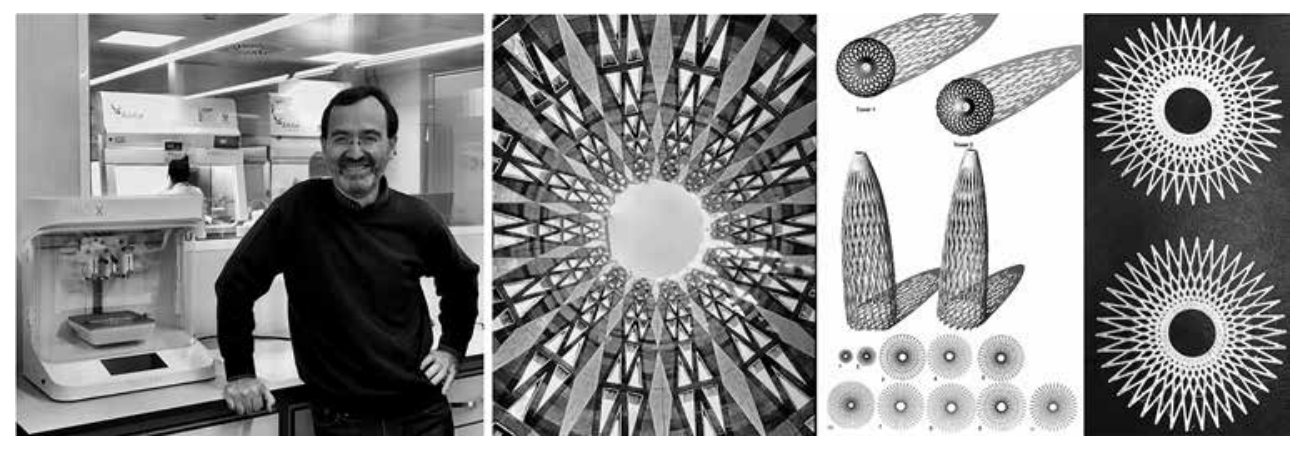

Figura 4. Izquierda, con la primera bioimpresora 3D del laboratorio. Centro izquierda, interior desde abajo de la torre de la Virgen María, aún en construcción, desde un punto de vista que luego ya no podrá verse, de la Basílica de la Sagrada Familia de Antoni Gaudí en Barcelona: se aprecian formas fractales formadas por un doble efecto, físico, de adelgazamiento paulatino de la torre, y óptico, por la ley de la perspectiva. Centro derecha y derecha, respectivamente, diversas versiones de diseños digitales de fractales para bio-manufacturing, y dos versiones fabricadas previamente con una impresora digital 3D. Diseños de Alberto T. Estévez - GenArqOffice (fotos del autor).

Es con todo esto que se encontrará para el Diseño muchos más recursos y posibilidades. Incluso mayor calidad, al aplicar mayor inteligencia, que al fin y al cabo es el máximo criterio de calidad. Aprendiendo de la maestra más sabia y de mayor experiencia, la naturaleza. Que lleva millones de años de ventaja en incontables experimentos de éxito en su gran laboratorio que es la Tierra. ¿Qué debe pensarse entonces que será "lo deseable"? Tomar ventaja de todo lo que ofrece la naturaleza. Confirmándose que la mejor manera de resolver los problemas que se encuentran en esta vida es con vida. Y más cuando es en este siglo 21 que la genética ya se ha hecho viable (Estévez, 2020c). Pues ya se está en un momento en el que, gracias a la genética se puede pensar en controlar el crecimiento de células vivas como material arquitectónico y de diseño, dejando así que objetos, paredes, casas, ciudades, paisajes crezcan solos, vivos. Algo que ahora es deseable, cuya viabilidad está a la puerta. Y se convierte en un deber declarar que la genética tiene un potencial enorme para resolver todas las necesidades humanas de la manera más sostenible, pues paradójicamente es solucionar con la misma naturaleza los problemas que la humanidad le ha creado.

Ahí se hace entonces relevante el preciso momento en que el crecimiento informal y espontáneo de las células se convierte en una estructura primigenia, capaz de empezar a resistir solicitaciones externas. Entonces, procedente de las investigaciones del autor que esto firma, sobre estructuras celulares con el microscopio electrónico, que permite ver tal crucial momento, surgió el proyecto de las Sporopollenin Houses (Estévez, 2009a). Se trata de casas unifamiliares (Figura 5) que "crecen" genéticamente constituidas por esporopolenina, un material propio de los granos de polen, el más durable, que no se pudre, ni se oxida, ni se deshace, aunque pasen miles de años. Y esto no carece de importancia, por 
cuanto la durabilidad es una exigencia en el campo de la arquitectura y del diseño. A su vez, por el cambio que supone algo así, bien podría contraponerse a la paradigmática casa Farnsworth de Mies, como comparativa entre ambos siglos, el 20 y el 21.
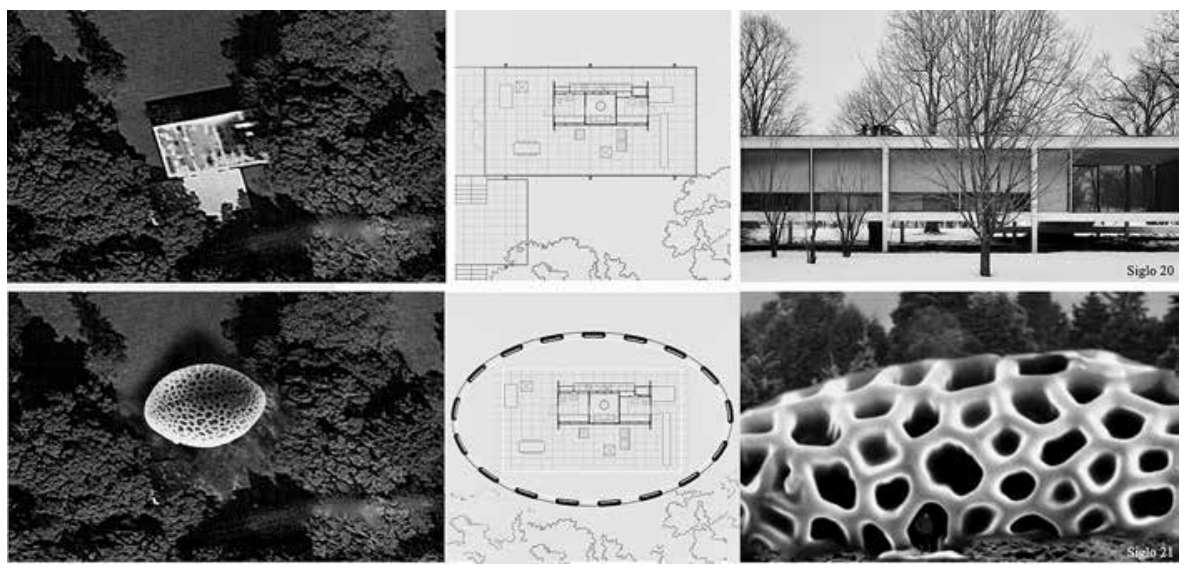

Figura 5. Arriba, Ludwig Mies van der Rohe, casa Farnsworth, Plano, 1945-50. Abajo, Alberto T. Estévez, Sporopollenin house, Barcelona, 2009-10. (Imagínese las fotos de abajo en color, como son originalmente, para entender mejor la comparación pretendida, entre los siglos 20 y 21, del blanco y negro al color).

Estas cuestiones fueron a su vez escenificadas en el proyecto para el Genetic Barcelona $\mathrm{Pa}$ vilion (Figura 6), a modo de reforma genética, blanda y comestible del German Barcelona Pavilion de Mies, en pos de una bio-manufacturing como alternativa a la digital-manufacturing. Siguiendo los pasos de este también paradigmático pabellón y su importancia para la Modernidad, con tal proyecto carnoso se busca presentar de manera simbólica un nuevo horizonte, donde la genética aplicada a la arquitectura ayude a resolver los problemas que conlleva el mundo de la edificación para nuestro siglo: adecuación, relevancia, compromiso. Así, se propuso este pabellón a modo de investigación sobre el control genético del crecimiento celular, con la idea de hacer crecer tejidos vivos como material constructivo (Estévez, 2009b). A su vez, el Genetic Barcelona Pavilion quedó incluido en una exposición pionera, la de "Bios 4: arte biotecnológico y ambiental", que tuvo lugar en el CAAC, Centro Andaluz de Arte Contemporáneo, Sevilla, el año 2007 (Estévez, 2020d). 


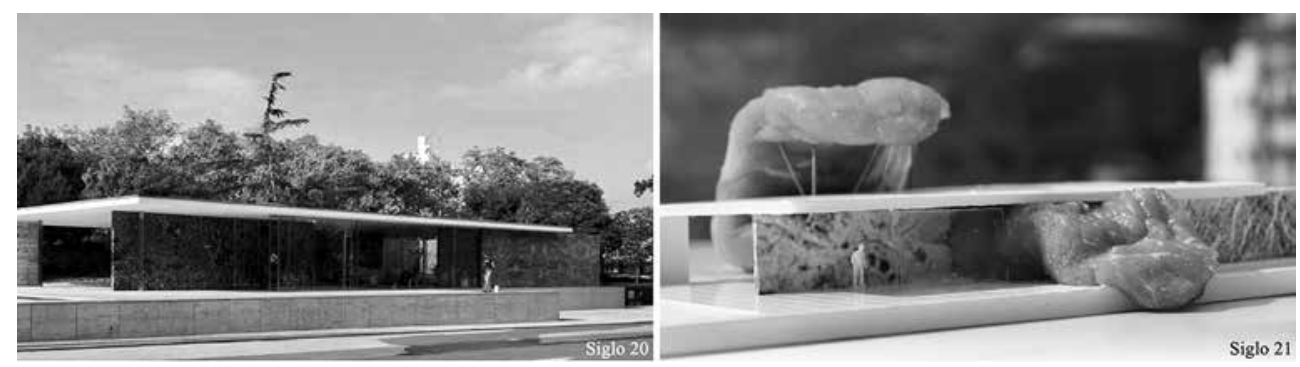

Figura 6. Izquierda, Ludwig Mies van der Rohe, German Barcelona Pavilion, Barcelona, 1929. Derecha, Alberto T. Estévez (con Marina Serer), Genetic Barcelona Pavilion, Barcelona, 2007. (Imagínese la foto de la derecha en color, como es originalmente, para entender mejor la comparación pretendida, entre los siglos 20 y 21, del blanco y negro al color)

Lamentablemente siempre se puede uno cruzar con alguien envidiosillo/a y malintencionado/a, que sólo sabe denostar a traición (sin turno de réplica) un quehacer que le queda muy lejos de su imaginación. Si por lo menos fuera perverso/a en lo publicado (no merece ni cita), aún podríamos sentarnos juntos a reírnos un rato, descubriendo sus oscuros entresijos. Sin embargo ni siquiera le llega la inteligencia para tanto. Y descubriendo su torpe precipitación, propia de quién no lee un mínimo para informarse mejor, critica que ese proyecto antes citado sólo sea una maqueta. Como si Mies tuviera menos mérito en 1922 al presentar su maqueta de rascacielos sin haber construido aún ni uno, o sus dibujos de 1921 y 1923, de su otro rascacielos y de su edificio de oficinas respectivamente (Figura 7) nunca erigidos. Pues, sí, es una maqueta, un deseo (algo deseable), y como hizo antes Mies, ¿quién no querría llenar el mundo de deseos? Y quizá con suerte alguno acabe haciéndose realidad. 

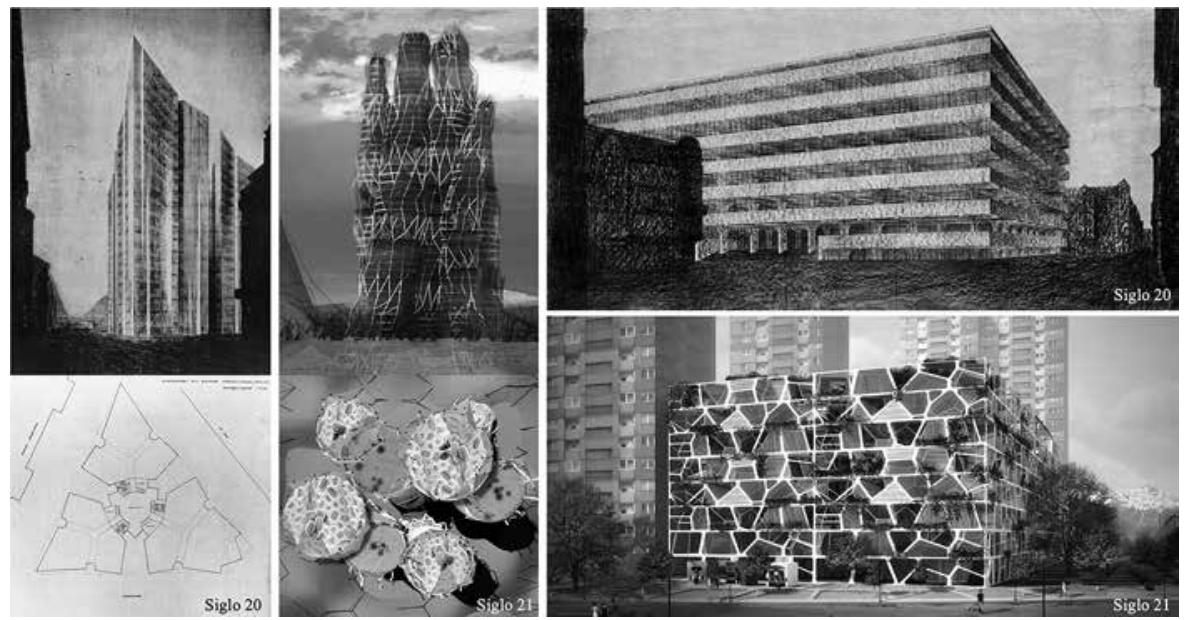

Figura 7. Izquierda, Ludwig Mies van der Rohe, rascacielos, Berlín, 1921. Centro, Alberto T. Estévez (con Aref Maksoud), rascacielos, Barcelona, 2008-09. Derecha arriba, Ludwig Mies van der Rohe, edificio de oficinas, Berlín, 1923. Derecha abajo, Alberto T. Estévez - GenArqOffice, edificio de viviendas, Innsbruck, 2014. (Imagínese las imágenes del centro y de abajo a la derecha en color, como son originalmente, para entender mejor la comparación pretendida, entre los siglos 20 y 21, del blanco y negro al color).

Comparativamente aquí, de lo factible a lo deseable, y no por ello ya menos viable, por parte de Mies en el siglo 20 se aporta un rascacielos y un edificio para oficinas, de geometría simple, con cerramientos de vidrio y hormigón, diseñados y fabricados manualmente, a lo sumo parcialmente con prefabricación, y con estructuras a tracción que permiten una dominante formal horizontal. Y por parte del que esto escribe en el siglo 21 se aporta un rascacielos y un edificio para viviendas (de refugiados el rascacielos), autosuficientes y verdes, contando con las ventajas de la arquitectura solar pasiva, de geometría compleja, con cerramientos de celosías de esponjas marinas (el rascacielos) y madera (el edificio), integrando agricultura urbana, diseñados y fabricados biológica y digitalmente, con estructuras a compresión y a tracción que permiten una dominante formal orgánica.

\section{En la tercera década del siglo 21, “a pesar de todo, dicho en el vacío es más...”}

A veces, especialmente cuando se habla de lo deseable, más allá de lo factible, o incluso de lo todavía no viable, da la sensación de que las palabras se dicen en el vacío, como ante paredes ciegas, sordas y mudas. Pareciera que la gente anda muy ocupada -o muy cómoda con lo conocido- como para detenerse a entender y/o poner por obra algo aún por venir. 
Sin embargo, decir todas estas cosas en el (aparente) vacío vale la pena. Es un deber decirlas para el que las ve... Es mejor decirlas que callarse... "Es más”, más que no decir nada... Aunque no las reciba ningún aplauso. Aunque por el contrario uno se vea arrinconado, más por el miedo que sigue a la envidia que por otra cosa. Aunque parezca "dicho en el vacío", con nadie escuchando. Esto pasa especialmente cuando se escribe. Y le pasaba a Loos, como para titular así su primer volumen recopilatorio de publicaciones. Ya vendrán las generaciones que sean más receptivas que las que sólo tienen en mente lo factible, como también le pasó a él, celebrándolo "a pesar de todo", como titularía su segundo volumen. Esto siempre ha sido así. Y sin embargo hace falta gente dedicada a lo factible. Si bien los más mediocres de entre ellos pensarán despectivamente que sólo son sueños, fantasías, utopías, de los que trabajan en lo deseable. Pero siempre habrá alguno que reconocerá admirado cómo son capaces de ver más allá de la frontera del conocimiento. Cuando al llegar a ella y ampliarla hacen que lo deseable tome la tortuosa senda de lo viable hasta llegar al remanso de lo factible.

En definitiva, como se ha anotado, "a pesar de todo, dicho en el vacío es más" que callar y no decir nada. Y por eso se ha hablado aquí de sostenibilidad, de ciencias y humanidades, para los diseñadores y para todo el que casualmente pase por estas páginas. Y se ha ilustrado con ejemplos de diseño biodigital, de aplicaciones de fabricación biológica y digital. Con suerte, con fortuna crítica que se llama, se verán frutos de esta recepción en no menos de 15 años, dentro de una generación.

Así que un deber clave de investigadores, profesionales y docentes del Diseño, que hay que tender a unificar esas tres facetas, es llevar el Diseño al campo de lo deseable. De manera que en cuanto se haga viable sean otros los que lo hagan factible, para ser siempre motores que arrastren a algo mejor, más adecuado a los tiempos cambiantes. Alguien tiene que hacerlo, y alguien tenía que decirlo. Sin duda, hoy, ya en la tercera década del siglo 21, Loos habría superado hace tiempo el pensar en "Ornamento y Delito", y Mies actuaría sin mínimos para conseguir lo máximo. Pues no trabajaban con lo factible sino con lo deseable, consiguiendo con su vida que fuera viable, para todos y todas.

\section{Referencias bibliográficas}

Barragán, L. (2000). Escritos y conversaciones. Madrid: El Croquis Editorial.

Estévez, A. T. (2009a). Arquitecturas genéticas III: nuevas técnicas biológicas y digitales. En A. T. Estévez (Ed.). Arquitecturas genéticas III: nuevas técnicas biológicas y digitales (pp. 14-27). Santa Fe / Barcelona: Sites Books / ESARQ (UIC).

Estévez, A. T. (2009b). Al margen: escritos de arquitectura. Madrid: Abada.

Estévez, A. T. (2019). Digital tools for architectural conception. En C. Marcos Alba (Ed.), Graphic Imprint: The influence of Representation and Ideation Tools in Architecture (pp. 1087-1097). Basilea: Springer International Publishing / Springer Nature.

Estévez, A. T. (2020a). La naturaleza es la solución. En D. V. Di Bella, y T. Irwin (Eds.), Cuadernos del Centro de Estudios de Diseño y Comunicación, núm. 105 (pp. 165-193). Buenos Aires: Universidad de Palermo - Carnegie Mellon University. 
Estévez, A. T. (2020b). Sustainable Living? Biodigital Future! En J. A. Stagner, y D. S-K. Ting (Eds.), Sustaining Resources for Tomorrow (pp. 137-162). Basilea: Springer International Publishing / Springer Nature.

Estévez, A. T. (2020c). The fifth element: biodigital \& genetics. En A. Vasel-Be-Hagh, y D. S-K. Ting (Eds.), Environmental Management of Air, Water, Agriculture, and Energy (pp. 195-212). Boca Raton: CRC Press / Taylor \& Francis Group.

Estévez, A. T. (2020d). Arquitectura biodigital y genética: adecuación, relevancia y compromiso. En I. Hernández García, R. Niño Bernal, y J. Hernández-García (Eds.), Paisajes artificiales: virtuales, informales y edificados (pp. 103-124). Bogotá: Pontificia Universidad Javeriana.

Estévez, A. T. y Urbano, J. (2020). Back to the Basics: Return to the Origin, Gaudí and Nature. En J. A. Stagner, y D. S-K. Ting (Eds.), Green Energy and Infrastructure: Securing a Sustainable Future (pp. 273-286). Boca Raton: CRC Press / Taylor \& Francis Group.

Loos, A. (1931). Trotzdem. Innsbruck: Brenner-Verlag.

Loos, A. (1993). Escritos. 2 volúmenes. A. Estévez, y J. Quetglas (Traductores). Madrid: El Croquis Editorial.

Mies van der Rohe, L. y Neumeyer, F. (1995). La palabra sin artificio: reflexiones sobre arquitectura 1922/1968. Madrid: El Croquis Editorial.

Sullivan, L. H. (1896). The tall office building artistically considered. Lippincott's Magazine, 57, Marzo 1896 (pp. 403-409). Filadelfia.

\begin{abstract}
It is clear that a good intention should be to think and act in a Design scenario that aims to have the maximum depth load. Squeezing neurons and time for it. It is a duty to the planet and society. And that will be better if precisely Design also opens up and settles between the fields of science and humanities.

On the other hand, it could be thought that what is feasible in Design would be above all what we already have experience in seeing it done. Although that would be like the past, it would be the known, it would be history, from Adolf Loos to Ludwig Mies van der Rohe. And if Design stays comfortably only with what is feasible, it will not be an agent of social and ecological change.

However, it could be said that what is viable would be like the present, of what we begin to have first examples or realistic prospects, what is being experienced in hand that it is seen that it will soon be feasible, and that it already acts influencing and guiding behaviors social. And finally, the desirable thing would be like the future, it would be to anticipate, it would be to project the vision to the frontier of knowledge, goals that you want to reach. Seeing that without even touching it, it would be a modifying factor of the material world. So the duty of Design researchers, professionals and teachers (that unifying these three facets gives a great advantage) would also be to open up and install Design in what is desirable. So that as soon as it becomes viable, others are dedicated to what is feasible, which therefore leaves them no time to prospect the feasibility of what is desirable. While those dedicated to research, profession and teaching continue to be the engine that drives some-
\end{abstract}


thing always better: today, already in the third decade of the 21 st century, Loos would have overcome thinking about "Ornament and Crime", and Mies would act without minimums to achieve what maximum, since they did not work with what is feasible but with what is desirable, achieving with their life and work that it was viable.

Keywords: Design - Interdisciplinary - Biological - Digital - Biodigital - Architecture Genetics - Ornament - Nature - Computing.

Resumo: É claro que uma boa intenção deve ser pensar e agir em um cenário de Design que visa ter a carga máxima de profundidade. Comprimindo neurônios e tempo para isso. É um dever para com o planeta e a sociedade. E isso será melhor se justamente o Design também se abrir e se instalar entre os campos das ciências e das humanidades.

Por outro lado, pode-se pensar que o que é viável em Design seria antes de tudo o que já temos experiência em vê-lo feito. Embora fosse como o passado, seria o conhecido, seria a história, de Adolf Loos a Ludwig Mies van der Rohe. E se o Design se acomoda apenas com o que é viável, não será um agente de mudança social e ecológica. Porém, poder-se-ia dizer que o que é viável seria como o presente, do que começamos a ter primeiros exemplos ou perspectivas realistas, o que está sendo vivido em mãos que se vê que em breve será viável, e que já atua influenciar e orientar comportamentos sociais. E por último, o desejável seria como o futuro, seria antecipar, seria projetar a visão para a fronteira do conhecimento, metas que você quer alcançar. Vendo isso sem nem mesmo tocá-lo, seria um fator modificador do mundo material.

Portanto, o dever dos pesquisadores, profissionais e professores do Design (que unir essas três facetas dá uma grande vantagem) também seria abrir e instalar o Design no que é desejável. Para que, tão logo se torne viável, outros se dediquem ao que é viável, o que, portanto, não lhes deixa tempo para prospectar a viabilidade do que é desejável. Enquanto os que se dedicam à investigação, à profissão e ao ensino continuam a ser o motor que move algo sempre melhor: hoje, já na terceira década do século XXI, Loos teria superado a pensar em "Ornamento e Crime", e Mies agiria sem mínimos atingir o máximo, já que não trabalharam com o que é viável, mas com o que é desejável, conseguindo com a vida e com o trabalho que era viável.

Palavras chave: Design - Interdisciplinar - Biológico - Digital - Biodigital - Arquitetura Genética - Ornamento - Natureza - Computação. 